\title{
Five-membered ring annelation in [2.2]paracyclophanes by aldol condensation
}

\author{
Henning Hopf ${ }^{* 1}$, Swaminathan Vijay Narayanan ${ }^{1}$ and Peter G. Jones ${ }^{2}$
}

\author{
Full Research Paper \\ Address: \\ ${ }^{1}$ Institut für Organische Chemie, Technische Universität \\ Braunschweig, Hagenring 30, D-38106 Braunschweig, Germany, Fax: \\ (+49) 531-391-5388 and 2Institut für Anorganische und Analytische \\ Chemie, Technische Universität Braunschweig, Postfach 3329, \\ D-38106 Braunschweig, Germany \\ Email: \\ Henning Hopf ${ }^{*}$ - h.hopf@tu-bs.de; Peter G. Jones - p.jones@tu-bs.de \\ * Corresponding author \\ Keywords: \\ aldol condensation; cyclopentadienones; cyclophanes; multibridged \\ cyclophanes; stereochemistry; X-ray analysis \\ Beilstein J. Org. Chem. 2014, 10, 2021-2026. \\ doi:10.3762/bjoc. 10.210 \\ Received: 27 June 2014 \\ Accepted: 15 August 2014 \\ Published: 28 August 2014 \\ Cyclophanes, Part 71. - For part 70, see [1] \\ Associate Editor: D. Y.-K. Chen \\ (c) 2014 Hopf et al; licensee Beilstein-Institut. \\ License and terms: see end of document.
}

\begin{abstract}
Under basic conditions 4,5,12,13-tetraacetyl[2.2]paracyclophane (9) cyclizes by a double aldol condensation to provide the two aldols 12 and 15 in a 3:7 ratio. The structures of these compounds were obtained from X-ray structural analysis, spectroscopic data, and mechanistic considerations. On acid treatment $\mathbf{1 2}$ is dehydrated to a mixture of the condensed five-membered [2.2]paracyclophane derivatives 18-20, whereas $\mathbf{1 5}$ yields a mixture of the isomeric cyclopentadienones 21-23. The structures of these elimination products are also deduced from X-ray and spectroscopic data. The sequence presented here constitutes the simplest route so far to cyclophanes carrying an annelated five-membered ring.
\end{abstract}

\section{Introduction}

We have reported in the past on numerous cyclophane derivatives bearing condensed four- to seven-membered rings, as shown by the representative examples of $\mathbf{1}\left(\mathrm{E}=\mathrm{CO}_{2} \mathrm{CH}_{3}\right)$ [2], 2 [3], 3 [4], and 4 [5]. Many of these compounds possess interesting structural and spectroscopic properties, and can be used as substrates for novel cyclophanes (Scheme 1).

For example, $\mathbf{2}$ has been converted into the corresponding bisolefin, from which multi-layered ferrocene complexes ("metallocenophanes") were prepared [6]. Analogously, from 4 several tropyliophane salts were obtained [5].
In the case of the cyclopentenone-annelated compounds 2 we previously prepared precursors such as $\mathbf{5}$ (easily available by Wittig-Horner reaction of the appropriate bis-formyl cyclophanes) and subjected them to catalytic hydrogenation followed by a double Friedel-Crafts cyclization.

However, it appeared to us that a more direct route to these useful phane derivatives could be developed by employing aldol-type reactions of the tetraacetyl derivative 9. This tetraketone (whose "twisted" structure was determined by singlecrystal X-ray analysis [7] as shown in Scheme 2) is readily 


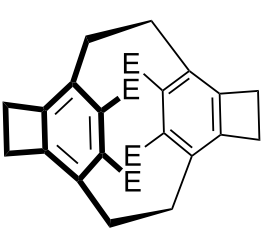

1

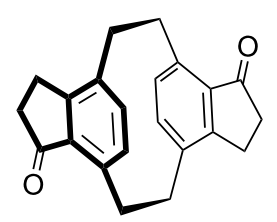

2

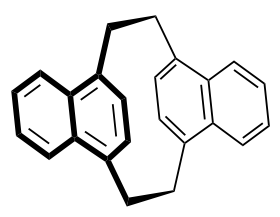

3

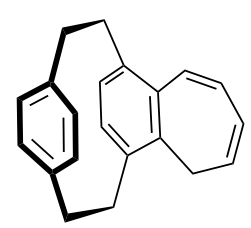

4

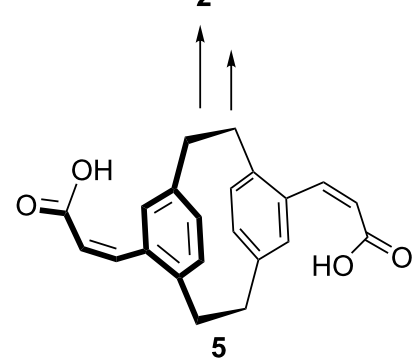

Scheme 1: [2.2]Paracyclophane derivatives with annelated alicyclic rings.

2<smiles>C=C=CC=C=C</smiles>

6
2<smiles>CC(=O)C(C)=O</smiles>

7
2<smiles>C=C(C)CCCC</smiles>

8

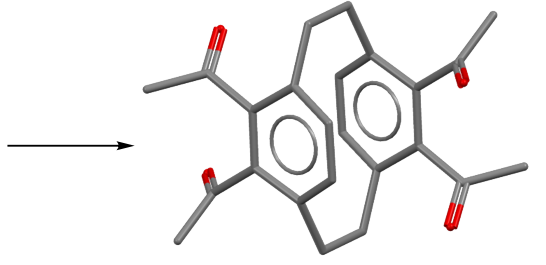

9

Scheme 2: The formation of the tetraketone 9 by a Diels-Alder addition.

available by adding hex-3-yne-2,5-dione (7) to the diene hexa$1,2,4,5$-tetraene $(6)$, passing through the $p$-xylylene intermediate 8 en route [7].

We were, furthermore, interested in studying the aldol reaction of 9 , since this process should pose several stereochemically interesting questions. As illustrated in Scheme 3, there are six different products that could be formed by an aldol cyclization of 9 (Scheme 3).

In the final product the two "surviving" carbonyl groups could point either in the same direction (syn-orientation, 10-12) or in opposite directions (anti-orientation, 13-15). Furthermore, the newly formed hydroxy group could either point towards the inner cavity of the cyclophane framework (endoorientation) or to the outer section of the derivative (exo-orientation). Thus altogether the six different diastereomers 10-15 result.

\section{Results and Discussion}

As the experiment shows (treatment of 9 with either sodium hydroxide in methanol or aniline in methanol, both at room temperature), only two of the possible six isomers (see above) are actually formed. To these we assign structures $\mathbf{1 2}$ and $\mathbf{1 5}$ (product ratio 30:70), i.e., the aldols are syn,endo,endo- and anti,endo,endo-isomers.

For the former compound the structure assignment follows from single-crystal X-ray analysis of its deuteriochloroform solvate. The asymmetric unit is shown in Figure 1. The structure of $\mathbf{1 2}$ displays approximate $C_{2}$ symmetry, with a r.m.s. deviation of $0.05 \AA$. It shows the normal distortions associated with the [2.2]paracyclophane geometry, with lengthened bridge bonds, widened $\mathrm{sp}^{3}$ bridge angles and narrowed $\mathrm{sp}^{2}$ ring angles at the bridgehead atoms, and boat-shaped six-membered rings with the bridgehead atoms lying out of the plane of the other four atoms (see Table 2 below). The crystal packing involves two classical and three "weak" hydrogen bonds (two involving the deuteriochloroform) that combine to form a complex threedimensional pattern (Table 1).

Several attempts to obtain crystals of the major isomer 15 suitable for X-ray analysis failed. The anti-orientation of the carbonyl groups of compound $\mathbf{1 5}$ was proved by the X-ray structural analysis of the product resulting from a dehydration experiment described below. 


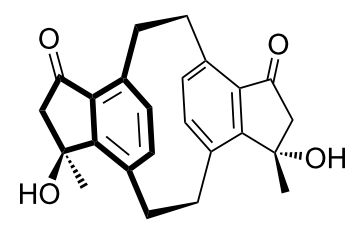

10

(syn,exo, exo)

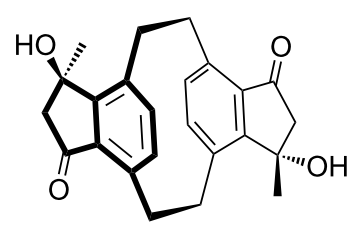

13

(anti,exo,exo)

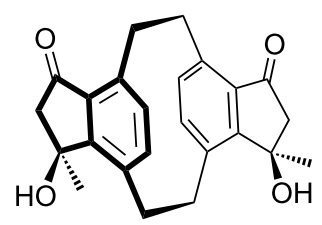

11

(syn,exo,endo)

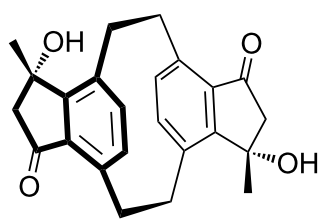

14

(anti,exo,endo)

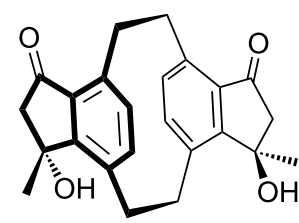

12

(syn,endo,endo)

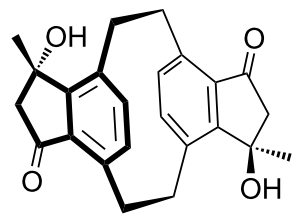

15

(anti,endo,endo)

Scheme 3: The possible structures of the aldols formed from 9

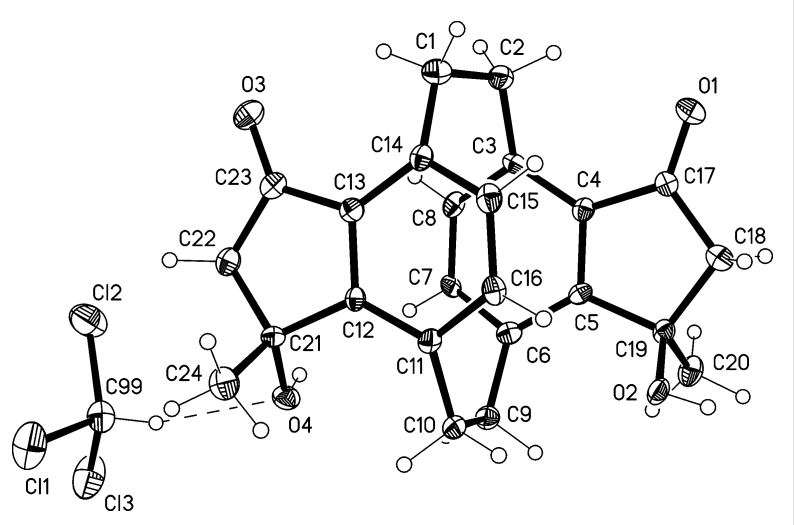

Figure 1: Structure of $12 \cdot \mathrm{CDCl}_{3}$ in the crystal. Ellipsoids represent $50 \%$ probability levels. Selected bond lengths $(\AA)$ and angles $\left({ }^{\circ}\right)$ : C1-C2 1.573(11), C9-C10 1.579(11), C14-C1-C2 112.8(7), C1-C2-C3 112.1(6), C6-C9-C10 113.0(7), C9-C10-C11 112.1(7), C4-C3-C8 114.8(8), C5-C6-C7 115.3(7), C12-C11-C16 116.2(7), C13-C14-C15 115.1(8). The dashed line indicates a weak hydrogen bond.
The most plausible mechanism for the above aldol reaction also favors the discussed structural assignments. As shown above in Scheme 2, the starting material 9 favors a conformation in the solid state in which all carbonyl groups point towards the "inner" space of the cyclophane core. In other words, the oxygen atom faces a methylene hydrogen atom of the bridge. In principle the alternative orientation is also possible, with the methyl substituent taking this position. A comparable situation has been observed for the 4-acetyl derivative of [2.2]paracyclophane, with the difference that the preferred endo-conformation has been observed both for the solid state [8-10] and in solution by NMR spectroscopy [11].

We hence assume that the conformation of 9 in solution resembles that of the solid state structure given in Scheme 2. With this assumption we can easily rationalize the formation of $\mathbf{1 2}$ and $\mathbf{1 5}$ in the aldol reaction, both containing endo-configurated $\mathrm{OH}$ groups only (Scheme 4).

Table 1: Hydrogen bonds $\left[\AA\right.$ and $\left.{ }^{\circ}\right]$ for $12 \cdot \mathrm{CDCl}_{3}{ }^{\mathrm{a}}$

\begin{tabular}{lllll}
$\mathrm{D}-\mathrm{H} \cdots \mathrm{A}$ & $\mathrm{d}(\mathrm{D}-\mathrm{H})$ & $\mathrm{d}(\mathrm{H} \cdots \mathrm{A})$ & $\mathrm{d}(\mathrm{D} \cdots \mathrm{A})$ & $<(\mathrm{DHA})$ \\
\hline $\mathrm{O}(2)-\mathrm{H}(02) \cdots \mathrm{O}(1) \# 1$ & 0.84 & 1.98 & $2.791(8)$ & 161.0 \\
$\mathrm{O}(4)-\mathrm{H}(04) \cdots \mathrm{O}(3) \# 2$ & 0.84 & 2.13 & $2.917(8)$ & 156.5 \\
$\mathrm{C}(7)-\mathrm{H}(7) \cdots \mathrm{O}(3) \# 2$ & 0.95 & 2.36 & $3.307(10)$ & 177.6 \\
$\mathrm{C}(22)-\mathrm{H}(22 \mathrm{~B}) \cdots \mathrm{Cl}(3) \# 5$ & 0.99 & 2.78 & $3.750(9)$ & 167.7 \\
$\mathrm{C}(99)-\mathrm{D}(99) \cdots \mathrm{O}(4)$ & 1.00 & 2.50 & $3.460(10)$ & 161.2 \\
\hline
\end{tabular}

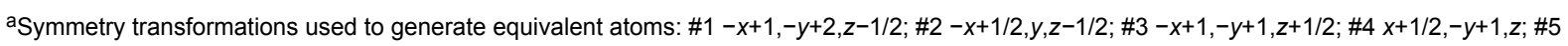
$-x+1 / 2, y, z+1 / 2$ 


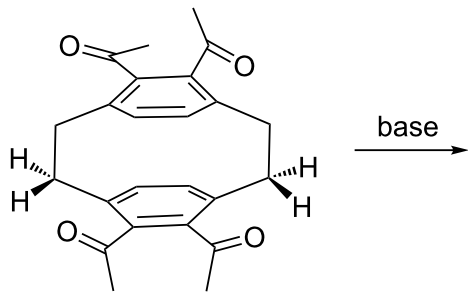

9

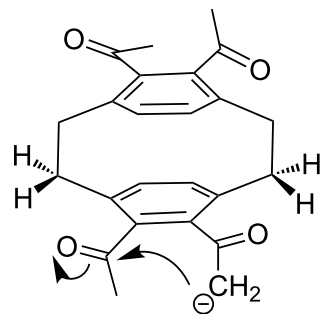

16

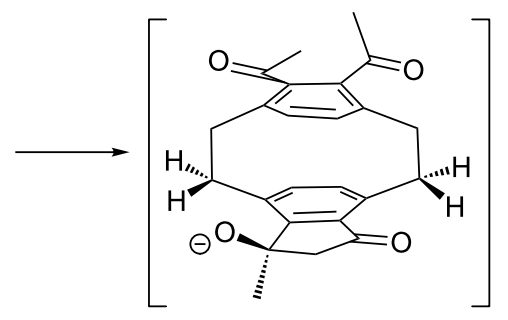

17
The reaction is initiated by proton abstraction from one of the acetyl groups $(\mathbf{9} \rightarrow \mathbf{1 6})$. The resulting enolate subsequently attacks the vicinal acetyl group, pushing the developing alcoholate function towards the methylene group, while the methyl substituent stays at the "outside" of the layered system. The intermediate $\mathbf{1 7}$ thus generated is then protonated to the corresponding aldol. Repetition of the whole process at the other deck of the cyclophane finally produces $\mathbf{1 2}$.

Presumably the same mechanism is followed during the formation of the main product $\mathbf{1 5}$, the only difference between the pathways being the enolate formation, i.e., whether the second five-membered ring is produced by deprotonating a syn- or antipositioned acetyl group.

To learn more about the chemical properties of the above aldols, we next dehydrated them under acidic conditions.

When the $s y n$-isomer 12 was treated with $p$-toluenesulfonic acid in toluene at room temperature, three dehydration products 18-20 were produced in approximately equal yields. The products were separated by preparative plate chromatography, and the conjugated derivatives $\mathbf{1 8}$ and $\mathbf{1 9}$ display a characteristic bright yellow color and show absorption maxima at 363 and $350 \mathrm{~nm}$ in the UV-vis spectrum, respectively. The unconju- gated isomer $\mathbf{2 0}$ is a colorless solid and possesses a UV maximum at $247 \mathrm{~nm}$. IR and NMR spectra (see Supporting Information File 1) support these structure assignments (Scheme 5).

It is interesting to note that for the formation of all three isomers an inwardly-oriented $\mathrm{OH}$ group of $\mathbf{1 2}$ has to be attacked; evidently there is enough room at this part of the substrate to enable protonation. The subsequent proton loss from the intermediately generated carbocation can proceed either by a Hofmann or a Saytseff mode, and - as the results show - both pathways are followed. Stereoelectronic reasons are presumably responsible for the slight preference of the Hofmann route. Not only does the methyl group appear to be sterically preferred for proton removal, it is also statistically favored. Furthermore, the newly produced cyclopentadienone ring possesses antiaromatic character and should hence be disfavored as compared to the non-conjugated methylencyclopentenone ring in $\mathbf{1 9}$ or $\mathbf{2 0 .}$

The anti-isomer 15 loses water under somewhat harsher conditions, and also furnishes three dehydration products, the anticonfigurated diketones 21-23, produced in a 1:3:1 ratio. Again the fully or partially conjugated isomers are deeply colored (intense yellow) and display absorption maxima at 389 and $358 \mathrm{~nm}$, respectively (Scheme 6).

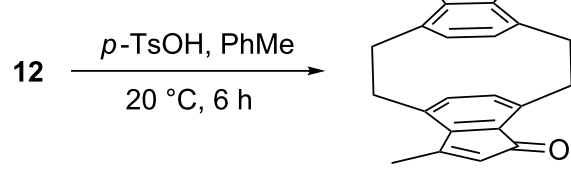

$18(30 \%)$

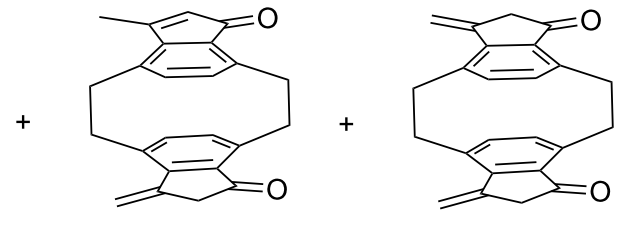

$19(30 \%)$

$20(37 \%)$ 


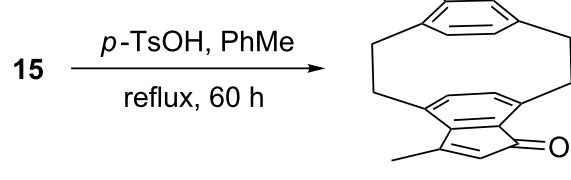

$21(16 \%)$

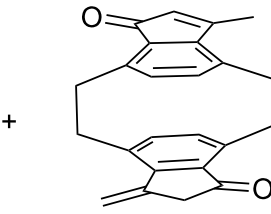

$22(48 \%)$

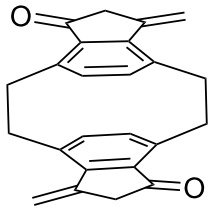

$23(16 \%)$

Scheme 6: Dehydration of the aldol 15.

For 21 yellow single crystals were obtained by recrystallization from pentane/chloroform to allow their X-ray structure determination in the solid state. The results are shown in Figure 2. The molecule displays crystallographic inversion symmetry (which precludes the use of standard cyclophane numbering to some extent). It shows the same type of distortions as discussed above for $\mathbf{1 2}$ (see Table 2).

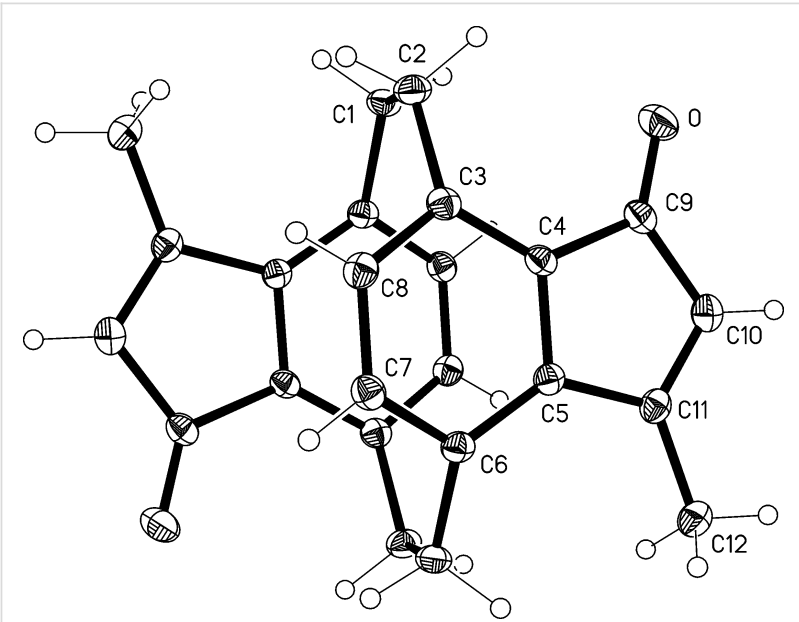

Figure 2: Structure of compound 21 in the crystal. Ellipsoids represent $50 \%$ probability levels. Selected bond lengths $(\AA)$ and angles $\left({ }^{\circ}\right)$ : C1-C2 1.589(2), C6'-C1-C2 112.9(1), C1-C2-C3 111.8(1), C4-C3-C8 115.3(1), C5-C6-C7 115.4(1).

This result clearly confirms our previous structure assignment of $\mathbf{1 5}$ as an anti-isomer. Although structures $\mathbf{1 3}$ and $\mathbf{1 4}$ for the initial aldol products cannot be excluded from the dehydration experiment, this alternative seems unlikely since it would require an aldol-formation step different from that discussed above (Scheme 4), i.e., one in which (several) of the carbonyl groups would point away from the ethano bridge. Based on the above structural results, there is no reason to assume this conformation to be preferred in the present case.

\section{Conclusion}

In summary, we have demonstrated in this study that aldol-type condensations constitute an attractive alternative to prepare [2.2]paracyclophane derivatives with annelated (and functional-
Table 2: Crystallographic data for $12 \cdot \mathrm{CDCl}_{3}$ and 21 .

$\begin{array}{lll}\text { Compound } & 12 \cdot \mathrm{CDCl}_{3} & 21\end{array}$

\begin{tabular}{lll}
\hline Formula & $\mathrm{C}_{25} \mathrm{H}_{24} \mathrm{DCl}_{3} \mathrm{O}_{4}$ & $\mathrm{C}_{24} \mathrm{H}_{20} \mathrm{O}_{2}$ \\
$M_{\mathrm{r}}$ & 496.81 & 340.40
\end{tabular}

Habit colourless plate yellow tablet

Cryst. size $(\mathrm{mm}) \quad 0.3 \times 0.12 \times 0.02 \quad 0.4 \times 0.2 \times 0.08$

Crystal system orthorhombic monoclinic

$\begin{array}{lll}\text { Space group } \quad P c a 2 & \text { C2/c }\end{array}$

Temperature $\left({ }^{\circ} \mathrm{C}\right) \quad-140 \quad-140$

Cell constants:

$\begin{array}{lll}a(\AA) & 19.286(3) & 14.051(2) \\ b(\AA) & 12.253(2) & 8.0225(12) \\ c(\AA) & 9.527(2) & 14.536(2) \\ \alpha\left(^{\circ}\right) & 90 & 90\end{array}$

$\beta\left(^{\circ}\right) \quad 90 \quad 96.695(6)$

$\mathrm{Y}\left({ }^{\circ}\right) \quad 90 \quad 90$

$V\left(\AA^{3}\right) \quad 2251.2 \quad 1627.5$

$Z \quad 4 \quad 4$

$D_{\mathrm{X}}\left(\mathrm{Mg} \mathrm{m}^{-3}\right) \quad 1.466 \quad 1.389$

$\mu\left(\mathrm{mm}^{-1}\right) \quad 0.44 \quad 0.09$

$F(000) \quad 1032 \quad 720$

$2 \theta_{\max } \quad 52.6 \quad 60$

Refl. measured $\quad 8580 \quad 9043$

Refl. indep. $\quad 3249 \quad 2394$

$\begin{array}{lll}R_{\text {int }} & 0.112 & 0.081\end{array}$

Parameters $\quad 413 \quad 119$

Restraints $293 \quad 0$

$w R\left(F^{2}\right.$, all refl. $) \quad 0.165 \quad 0.140$

$\begin{array}{lll}R(F,>4 \sigma(F)) & 0.091 & 0.051\end{array}$

$S \quad 1.19 \quad 1.06$

$\max . \Delta \rho\left(\mathrm{e} \AA^{-3}\right) \quad 0.43 \quad 0.45$

ized) five-membered rings, making these derivatives easily available for further transformations.

\section{Supporting Information}

\section{Supporting Information File 1}

Experimental part.

[http://www.beilstein-journals.org/bjoc/content/

supplementary/1860-5397-10-210-S1.pdf] 


\section{References}

1. Dix, I.; Bondarenko, L.; Jones, P. G.; Oeser, T.; Hopf, H. Beilstein J. Org. Chem. 2014, 10, 2013-2020. doi:10.3762/bjoc.10.209 See for the previous publication in this series see.

2. Hopf, H.; Hinrichs, H.; Ernst, L.; Jones, P. G.; Boekelheide, V. Isr. J. Chem. 2012, 52, 149-155. doi:10.1002/ijch.201100093

3. Hopf, H.; Raulfs, F.-W. Isr. J. Chem. 1985, 25, 210-216. doi:10.1002/ijch.198500033

4. Kleinschroth, J.; Hopf, H. Tetrahedron Lett. 1978, 19, 969-972. doi:10.1016/S0040-4039(01)85427-7

5. Ramm, S. M.; Hopf, H.; Jones, P. G.; Bubenitschek, P.; Ahrens, B.; Ernst, L. Eur. J. Org. Chem. 2008, 2948-2959. doi:10.1002/ejoc.200800171

6. Hopf, H.; Raulfs, F.-W.; Schomburg, D. Tetrahedron 1986, 42, 1655-1663. doi:10.1016/S0040-4020(01)87582-7

7. Narayanan, S. V.; Hopf, H.; Jones, P. G. Acta Crystallogr., Sect. E 2006, 62, o2125-02126. doi:10.1107/S1600536806015261

8. Jones, P. G.; Bubenitschek, P.; Hopf, H.; Pechlivanidis, Z. Z. Kristallogr. 1993, 208, 136-138. doi:10.1524/zkri.1993.208.Part-1.136

9. Jones, P. G.; Hopf, H.; Hillmer, J. Acta Crystallogr., Sect. E 2002, 58 o300-0302. doi:10.1107/S1600536802002933 See for the crystal structure of 4, 13-diacetyl-[2.2]paracyclophane.

10. Jones, P. G.; Bubenitschek, P.; Hopf, H.; Kaiser, B. Z. Kristallogr. 1995 , 210, 550-551. doi:10.1524/zkri.1995.210.7.550

See for the crystal structure of 4-(2'-naphthoyl)-[2.2]paracyclophane.

11. Laue, T. Monosubstituierte [2.2]Paracyclophane - zur Stereochemie planchiraler Verbindungen. Ph.D. Thesis, University of Braunschweig, 1991.

\section{License and Terms}

This is an Open Access article under the terms of the Creative Commons Attribution License

(http://creativecommons.org/licenses/by/2.0), which permits unrestricted use, distribution, and reproduction in any medium, provided the original work is properly cited.

The license is subject to the Beilstein Journal of Organic Chemistry terms and conditions:

(http://www.beilstein-journals.org/bjoc)

The definitive version of this article is the electronic one which can be found at: doi:10.3762/bjoc. 10.210 